\title{
Logistic Operating Curves in Theory and Practice
}

\author{
Peter Nyhuis and Matthias Schmidt \\ Institute of Production Systems and Logistics, \\ Leibniz Universitaet Hannover
}

Germany

\section{Introduction}

The Competitiveness of a company is determined by its ability to adjust its product offerings and performance to the changing market needs and its capability to realize the existing potentials in purchasing, production and distribution. Therefore, the long-term survivability of a company is measured by target values like relative competitive position, growth in sales, increase in productivity and the return on equity. At the same time, delivery reliability and delivery time have established themselves as equivalent buying criteria alongside product quality and price (Enslow, 2006; Hon, 2005; Wildemann, 2007;). High delivery reliability and short delivery times for companies demand high schedule reliability and short throughput times in production (Kim and Duffie, 2005). In order to manufacture efficient under such conditions, it is necessary to generate a high logistic performance and to minimise logistic costs simultaneously (figure 1) (Wiendahl, 1997).

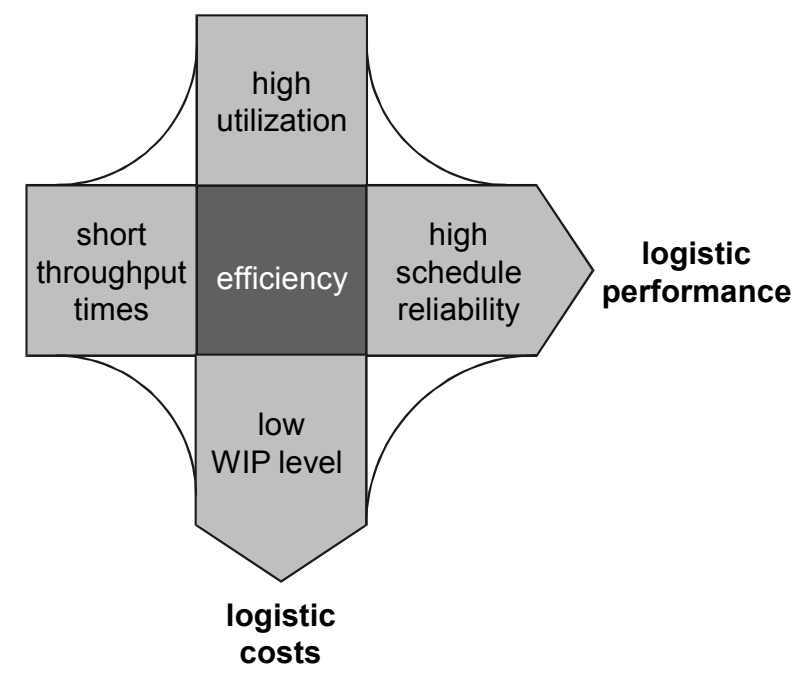

Fig. 1. Objectives of Production Logistics. 
The logistic performance is defined by short throughput times and high schedule reliability. The logistic costs depend on low WIP levels in production and high utilisation of operational resources.

\section{Challenges for production management}

The above mentioned production logistics objectives short throughput times, high schedule reliability, low WIP level and high machine utilisation can not be reached simultaneously because the objectives show a conflicting orientation (figure 2). This fact is known as the scheduling dilemma (Hopp and Spearman, 2000; Gutenberg, 1951). For example, it is not possible to maximise the utilisation of a work system and to minimise throughput times simultaneously. On the one hand a high utilisation of work systems calls for high WIP levels in order to prevent interruptions to the materials flow during production. On the other hand high WIP levels lead to long throughput times because of long material queues at work station. That means that the aim of high machine utilisation in conjunction with short throughput times cannot be achieved. In addition, long throughput times increase the likelihood of orders queuing at work systems being swapped around. The result is a decrease in the schedule reliability within the production. Several authors have pointed out that the challenge for managers therefore is not to "optimise" a certain logistic objective, but rather to find a rational trade-off between satisfactory levels of performance of all the conflicting objectives (Hopp and Spearman, 2000; Schuh, 2006; Schönsleben, 2004). In order to overcome the scheduling dilemma, certain work systems and production areas must be positioned in the field of conflict between the production logistics objectives. To do this, it is necessary to map the relationships between the effects of these different objectives and to describe the behaviour of the logistic system. The Logistic Production Operating Curves outlined in figure 2 provide a suitable approach. These curves describe the utilisation and the throughput times depending on the WIP level.

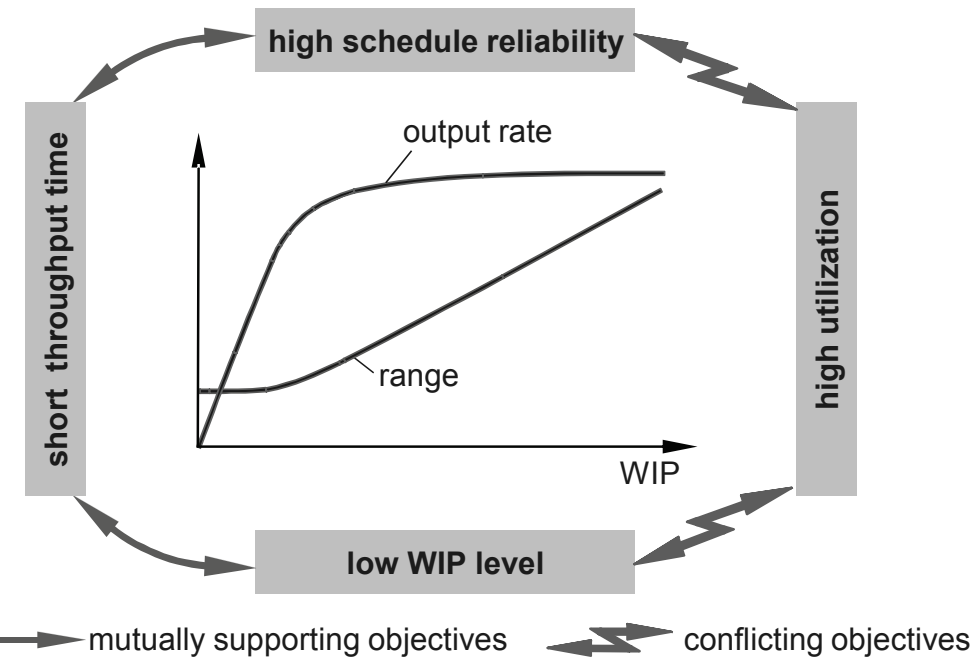

Fig. 2. Scheduling Dilemma and Logistic Production Operating Curves. 
Both research and industrial practice use various methods to model the described relationships. Popular methods are the queuing theory from the field of operations research, simulation and the Theory of Logistic Operating Curves developed at the Institute of Production Systems and Logistics (IFA). Figure 3 shows a qualitative comparison of the modelling methods by the criteria illustration quality and implementation efforts as well as the extension in industrial practice.

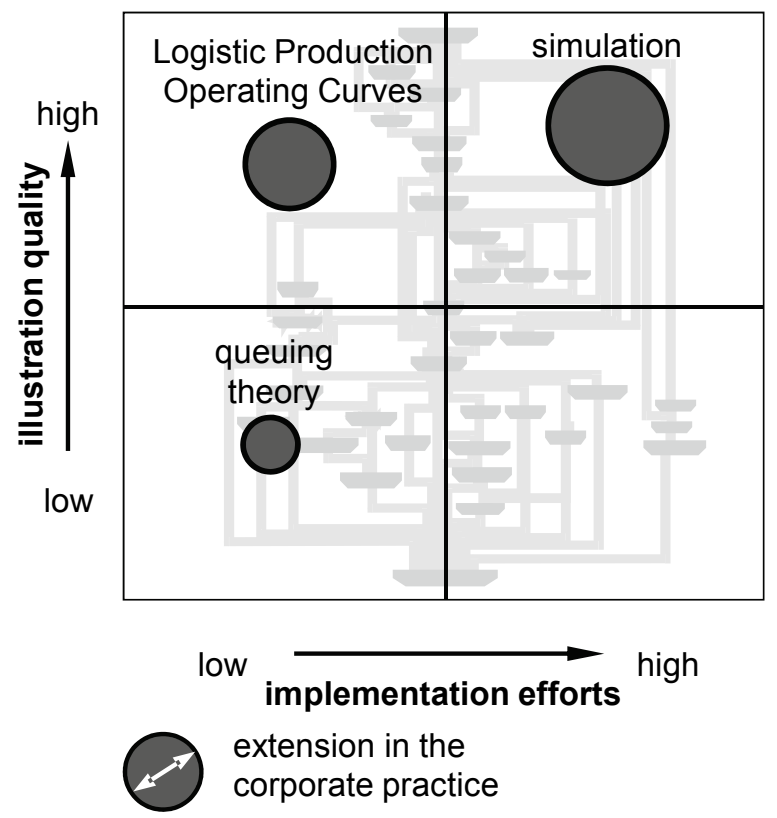

Fig. 3. Illustration Quality and Implementation Efforts of Different Modelling Methods.

Both the queuing theory and the Logistic Production Operating Curves require low illustration efforts while a high illustration quality can only be provided by the simulation and the Logistic Production Operating Curves, which both are widespread in industrial practice. Therefore, the queuing theory and simulation are often not entirely suitable for modelling logistic relationships, especially for the description of real production contexts (Nyhuis et al., 2005).

\section{Derivation of the Logistic Production Operating Curves}

The Logistic Production Operating Curves reduce the complexity and the cost of modelling the behaviour of logistic systems. Thus, they create a way of positioning a work system or a production area in the field of conflict between the logistic objectives. This chapter shows the derivation of the Logistic Production Operating Curves (Nyhuis and Wiendahl, 2009). Firstly, equations are developed for assumed ideal production conditions and result in ideal Logistic Production Operating Curves. Secondly, the ideal curves are adapted to real production processes. Thirdly, the validation of the Logistic Production Operating Curves is presented. 


\subsection{Logistic Production Operating Curves}

The development of the ideal Logistic Production Operating Curves requires to define an ideal production process. In this process, a single work system is considered. The utilisation of this work system is about $100 \%$ and the WIP level is at its minimum. This originates in the fact that a new order is fed to the work system whenever a completed order leaves it. Accordingly, no order has to wait for processing and no interruptions to the materials flow occur in the production process. The resulting throughput diagram is shown on the left in figure 4 .
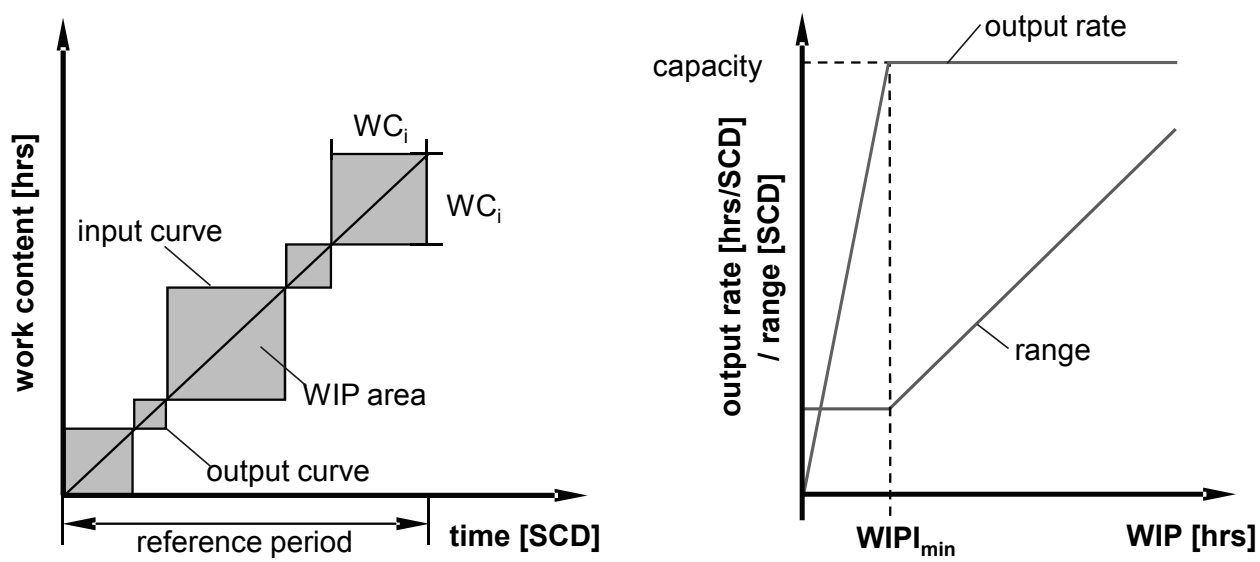

Fig. 4. Ideal Throughput Diagram and Ideal Logistic Production Operating Curves.

In the ideal process, the mean WIP level at the work system is governed exclusively by the work content (order times) and their scatter. This is called the ideal minimum WIP level:

$$
\mathrm{WIPI}_{\min }=\mathrm{WC}_{\mathrm{m}} \cdot\left(1+\mathrm{WC}_{\mathrm{v}}^{2}\right) \text {. }
$$

$\mathrm{WIPI}_{\min } \quad$ ideal minimum WIP level [hrs]

$\mathrm{WC}_{\mathrm{m}} \quad$ mean work content [hrs]

$\mathrm{WC}_{\mathrm{V}} \quad$ variation coefficient for work content [-]

[Note: hrs $=$ hours]

The upper limit to the output rate of the work system is defined by the maximum possible output rate. This is described by the restrictive capacity factors operational and personnel resources:

$$
\text { ROUT }_{\max }=\min \left(\mathrm{CAP}_{\mathrm{mc}}, \mathrm{CAP}_{\mathrm{op}}\right)
$$

ROUT $_{\max } \quad$ maximum possible output rate [hrs/SCD]

$\mathrm{CAP}_{\mathrm{mc}} \quad$ available machine capacity [hrs/SCD]

$\mathrm{CAP}_{\text {op }} \quad$ available operator capacity [hrs/SCD]

[Note: SCD = shop calendar day]

The ratio of mean WIP level to mean output rate corresponds to the mean range of the WIP level. This relationship is designated the funnel equation:

$$
\mathrm{R}_{\mathrm{m}}=\mathrm{WIP}_{\mathrm{m}} / \mathrm{ROUT}_{\mathrm{m}}
$$


$\mathrm{R}_{\mathrm{m}} \quad$ mean range [SCD]

$\mathrm{WIP}_{\mathrm{m}} \quad$ mean WIP level [hrs]

ROUT $_{m} \quad$ mean output rate [hrs/SCD]

The ideal Production Operating Curves, shown on the right in figure 4, can be derived from the ideal minimum WIP level and the maximum possible output rate. The Logistic Operating Curve of the output rate of a work system describes how the mean output rate varies with respect to the mean WIP level. In the ideal process, full utilisation of the work system and hence also the maximum possible output rate is achieved with the ideal minimum WIP level. A further increase in the WIP level does not bring about any increase in the output rate. And below the ideal minimum WIP level, the output rate drops in proportion to the WIP level until both values reach zero. The Logistic Operating Curve of the range can be calculated from the output rate operating curve with the help of the funnel equation. Above the ideal minimum WIP level, the range increases in proportion to the WIP level. Below the ideal minimum WIP level, the mean range corresponds to the minimum range which is due to mean order work content.

\subsection{Real Production Operating Curves}

Ideal process conditions do not occur in practice. However, a simulation carried out at the IFA showed that although the ideal Logistic Production Operating Curves do not represent real process conditions they provide a suitable framework. The simulation covered eight simulation experiments with the mean WIP level as the only changing variable (figure 5).

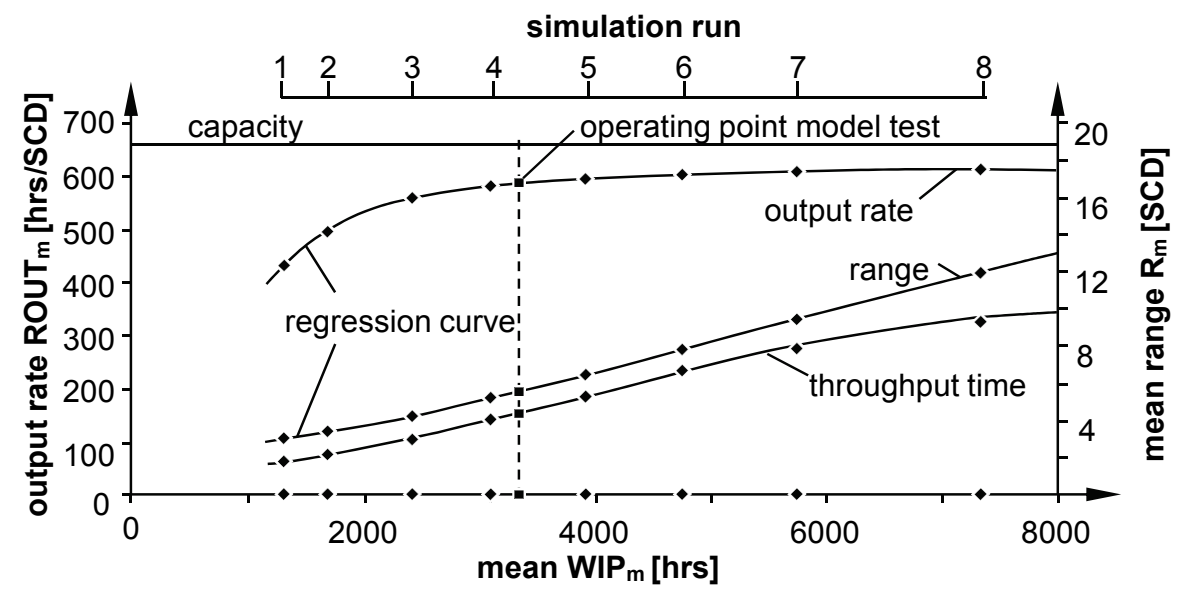

Fig. 5. Simulated Logistic Production Operating Curves.

The simulated operating states show clearly that the Logistic Production Operating Curves do not exhibit a defined break point under real process conditions. Instead, we see a smooth transition from the full machine utilisation zone of the operating curve (stable output, in this case WIP level approximately $5000 \mathrm{~h}$ ) to the under-utilised zone.

In order to be able to model real process conditions with minimum effort but adequate accuracy, we require a mathematical description of the real Logistic Production Operating Curves. An approximation equation was developed for the mathematical description based on an approximation of the parameterised $\mathrm{C}_{\mathrm{Norm}}$ function: 


$$
x=x(t)=t \text { and } y=y(t)=-(1-t c)^{1 / c}
$$

$\begin{array}{ll}\mathrm{x} & \text { variable [-] } \\ \mathrm{t} & \text { running variable [-] } \\ \mathrm{y} & \text { variable [-] } \\ \mathrm{C} & \mathrm{C}_{\text {Norm }} \text { parameter [-] }\end{array}$

The parameterised $\mathrm{C}_{\mathrm{Norm}}$ function has been transformed into the approximation equation in four steps. The four transformation steps required are shown in figure 6. Firstly, the set of equations (see formula 4) is translated by the value one in the positive y-direction. The second transformation step stretches the set of equations in the y-direction such that the maximum value $\mathrm{y}_{1}$ of the curve corresponds to the maximum possible output rate. The third transformation step shears the set of equations in the $\mathrm{x}$ direction.

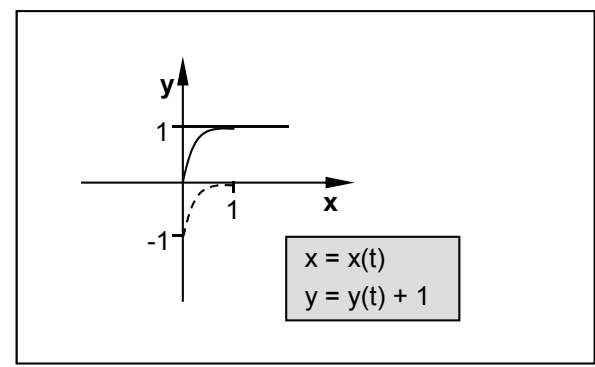

1) switching (y direction)

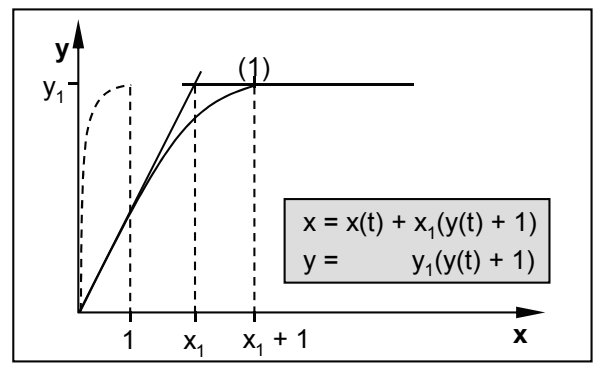

3) shearing ( $x$ direction)

--- original function for each transformation step

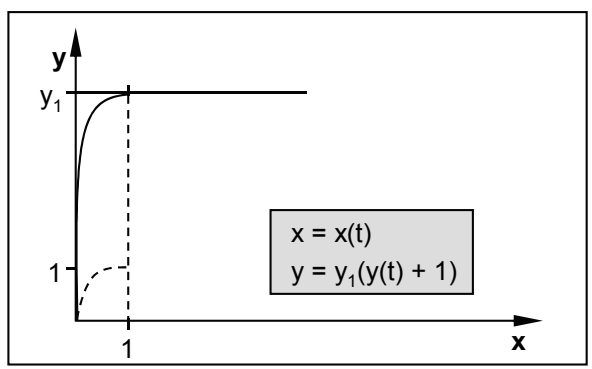

2) stretching (y direction)

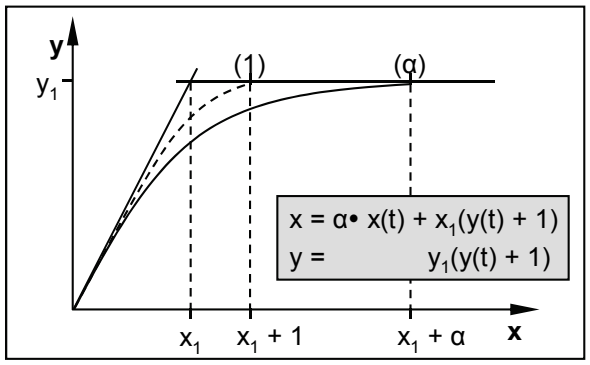

4) stretching ( $x$ direction)

Fig. 6. Transformation of the $\mathrm{C}_{\text {Norm }}$ Function.

The ideal Logistic Operating Curve of the output rate characterised by the ideal minimum WIP level now forms the system of coordinates for the real Production Operating Curves. The fourth transformation step stretches the curve by the stretch factor $\alpha_{1}$ in the $x$ direction. Replacing the variables $\mathrm{x}$ and $\mathrm{y}$ by the mean WIP level and the mean output rate respectively as well as the variables $\mathrm{x}_{1}$ and $\mathrm{y}_{1}$ by the ideal minimum WIP level and the maximum output rate respectively enables the transformed set of equations to be converted into the following set of equations. This describes the real Logistic Production Operating Curves of the output rate:

$$
\mathrm{WIP}_{\mathrm{m}}(\mathrm{t})=\mathrm{WIPI}_{\min } \cdot\left(1-\left(1-\mathrm{t}^{\mathrm{c}}\right)^{1 / c}+\mathrm{WIPI}_{\min } \cdot \alpha 1 \cdot \mathrm{t}\right.
$$




$$
\operatorname{ROUT}_{m}(t)=\operatorname{ROUT}_{\text {max }} \cdot\left(1-\left(1-\mathrm{t}^{\mathrm{c}}\right)^{1 / \mathrm{c}}\right.
$$

$\mathrm{WIP}_{\mathrm{m}}(\mathrm{t}) \quad$ mean WIP level (as a function of $\mathrm{t}$ ) [hrs]

$\mathrm{t}$

WIPI $_{\text {min }} \quad$ ideal minimum WIP level [hrs]

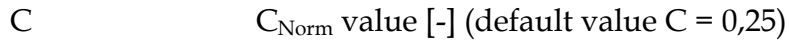

$\alpha_{1} \quad$ stretch factor [-] (default value $\alpha_{1}=10$ )

$\operatorname{ROUT}_{\mathrm{m}}(\mathrm{t}) \quad$ mean output rate (as a function of $\mathrm{t}$ ) [hrs/SCD]

$\mathrm{ROUT}_{\max }$ maximum output rate [hrs/SCD]

A pair of values for the mean WIP level and the mean output rate can be calculated for a given ideal minimum WIP level and maximum possible output rate for every value of $t(0 \geq$ $t \geq 1$ ). The combination of several such pairs of values results in the Logistic Operating Curve of the output rate. This curve can now be converted into the Logistic Production Operating Curve of the range with the help of the funnel equation (see formula 3).

The parameters of the approximation equations deduced, which describe the Logistic Production Operating Curves, take into account a series of production logistics factors (figure 7). These are included in the parameters for ideal minimum WIP level, maximum possible output rate and stretch factor $\alpha_{1}$. The batch size of the orders, the individual processing times for the products and the setup time necessary for the work systems are included in the calculation of the ideal minimum WIP level. In addition, by extending the scope of the study we can also include transport times and minimum inter-operation times (e.g. due to technological restrictions). The maximum possible output rate is mainly limited by the capacity of the work system. Furthermore, faults that reduce capacity, the level of

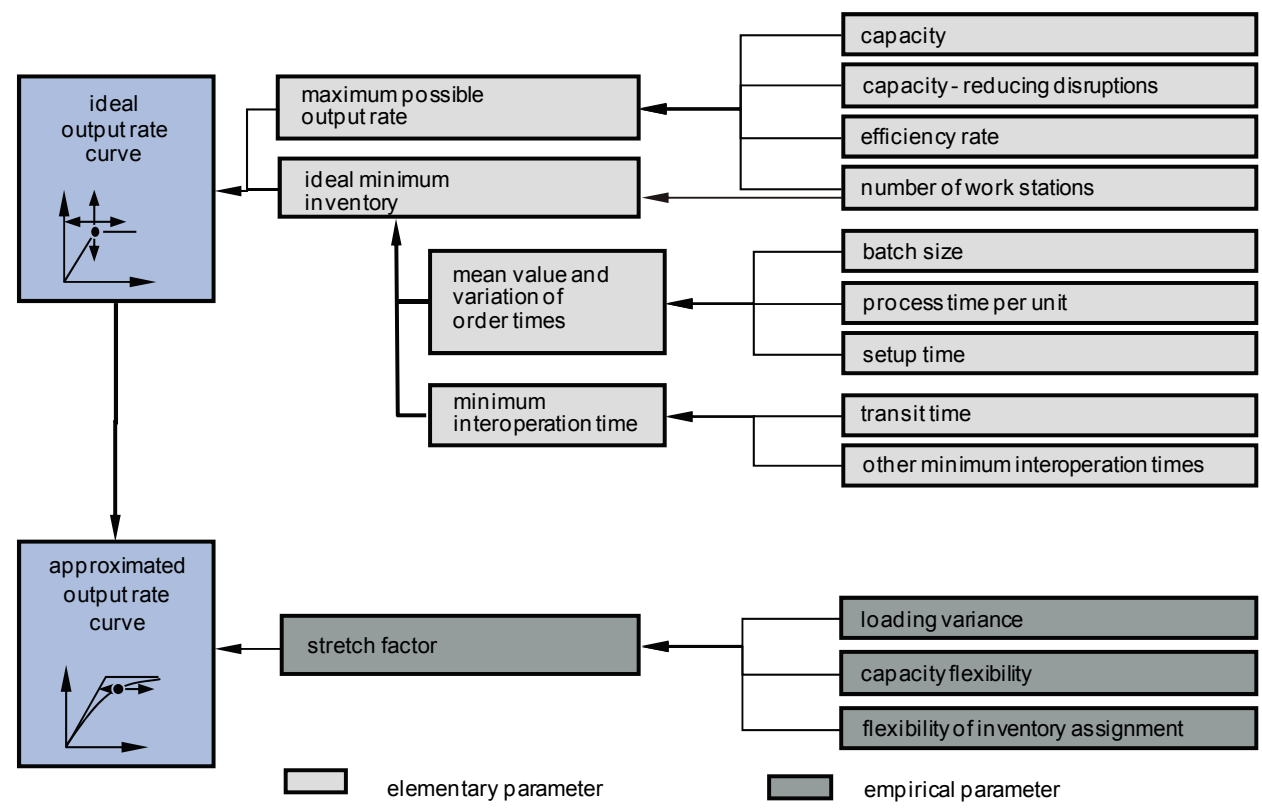

Fig. 7. Parameters of Logistic Production Operating Curves. 
performance and, lastly, the number of work systems determine the maximum possible output rate. The stretch factor $\alpha_{1}$, which until now could only be calculated empirically, is essentially determined by the capacity flexibility available on the one hand and the scatter of the workload on the other.

\subsection{Validating the Real Production Operating Curves}

The Logistic Production Operating Curves describe the relationships between the effects of the logistic performance measures of a work system for constant order time and capacity structures. As different WIP levels for a work system are hardly feasible in practice for identical order time and capacity structures, the real Production Operating Curves are validated by means of simulations (fig. 8).

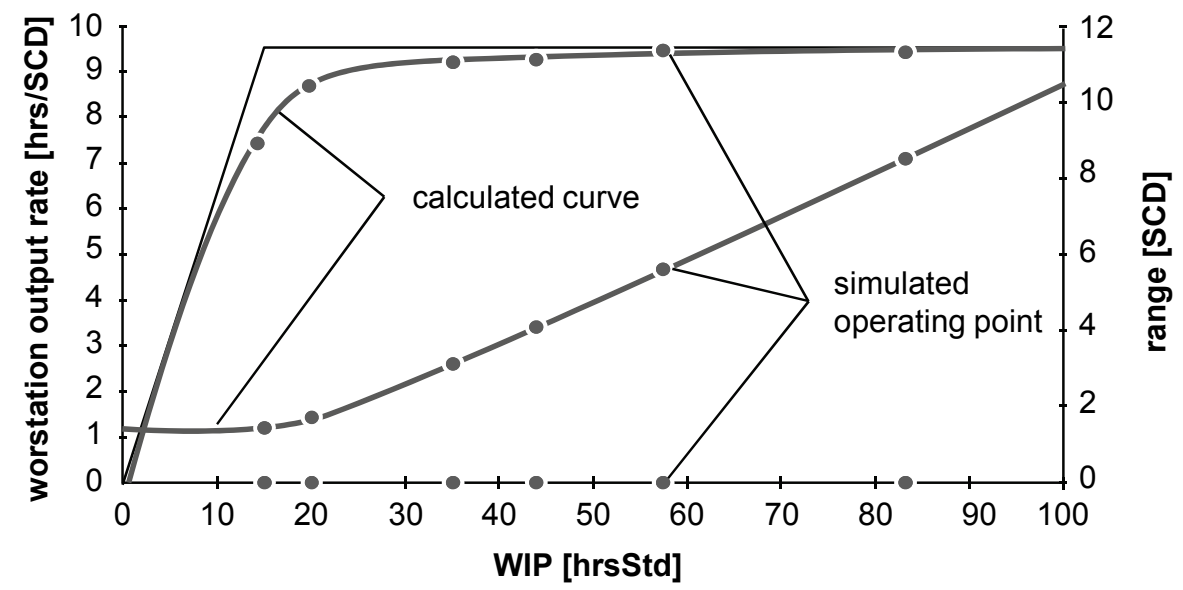

Fig. 8. Simulation based Validation of Logistic Production Operating Curves.

The results of the simulation work carried out at the IFA reveal a high correlation between the result of the simulation and the Logistic Production Operating Curves calculated. Analyses of the deviation resulted in an average divergence of less than $2 \%$ between the calculated and the simulated operating conditions. The simulations prove that the mathematical model describes the behaviour of the simulated work system with sufficient accuracy.

The mathematical model of the Logistic Production Operating Curves was developed for practical applications and therefore additional validation under industrial operating conditions was necessary. The practical trials carried out exhibit a high correlation with the findings of the model. Therefore, the mathematical model of the Logistic Production Operating Curves has been proved as suitable for practical application. The procedure for validating the model by means of practical trials is as follows.

Feedback data from a work system was evaluated within the scope of the analyses of throughput time and WIP level. The operating condition of the work system is given by the analysis, and this result is subsequently compared with a calculated Logistic Production Operating Curve which initially uses a default value $\left(\alpha_{1}=10\right)$ for the stretch factor $\alpha_{1}$. If a comparison of the operating condition and the calculated Production Operating Curve does 
not reveal any significant differences with respect to possible machine utilisation losses due to WIP level, the parameterising of the model can be regarded as suitable. If this is not the case, the stretch factor $\alpha_{1}$ must be modified. Only in those cases with very high WIP levels it is impossible to check the parameters in this way. However, this limitation does not usually represent a problem in practice because in these cases the options for reducing the WIP level are obvious.

\subsection{Normalized Logistic Production Operating Curves}

For a number of problems it is helpful to normalize reference parameters in order to be able to draw conclusions that are independent of the system specific conditions or to compare different work systems with the help of the Logistic Production Operating Curves. In order to do so it is necessary to determine appropriate reference values for such normalisations. It seems obvious that for the output rate and WIP level they can be based on the ideal operating state and thus expressed as a relative parameter.

In our discussion about Output Rate Operating Curves we already conducted a similar type of normalization, using the definition of the mean WIP dependent utilization $U_{m}$ as a ratio of ROUT $_{m}$ to ROUT $_{\max }$. In order to describe a relative WIP level, the mean WIP is set in relation to $\mathrm{WIPI}_{\text {min }}$.

Fig. 9 shows the normalized Logistic Production Operating Curves, where $a_{1}=10$. The graph describes how a change in the WIP impacts the utilization of the workstation, independent of the existing work content structures and the workstation's capacity. It shows, for example, that the WIP dependent loss of utilization is approximately $17 \%$ when

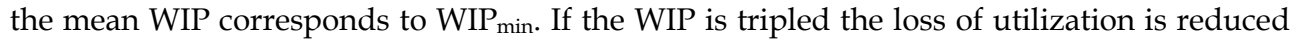
to approximately $1 \%$.

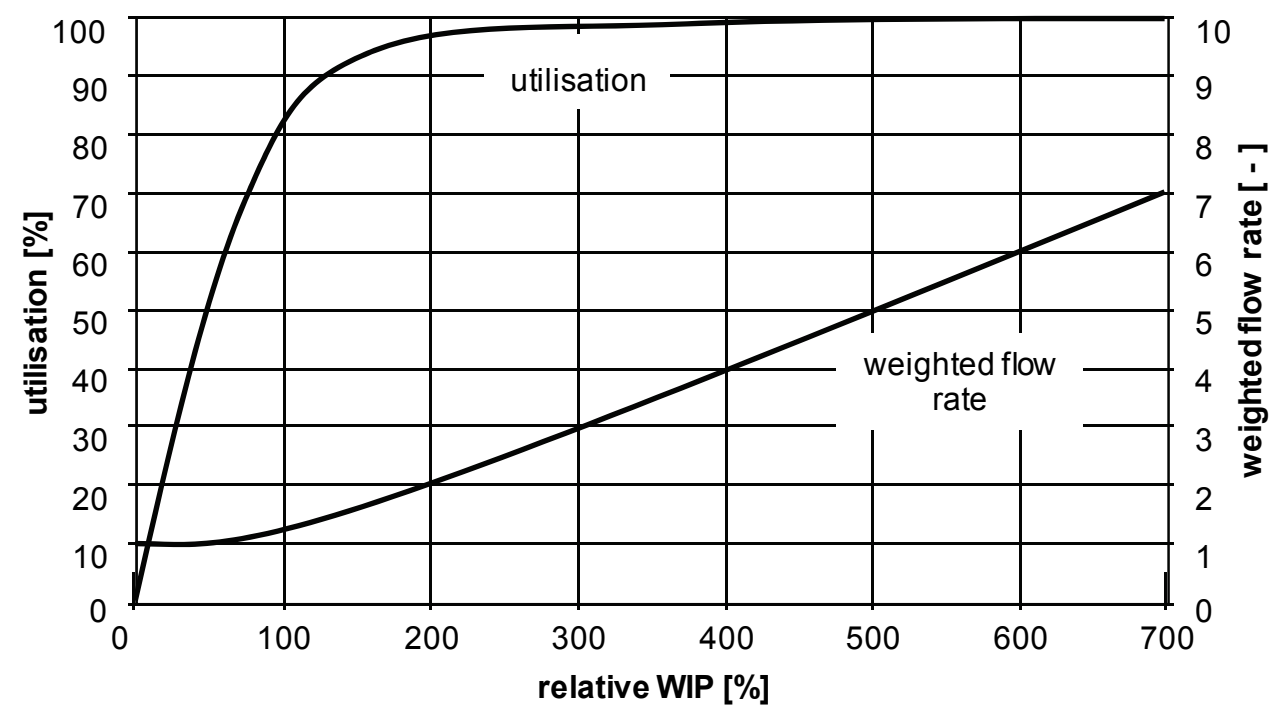

Fig. 9. Normalised Logistic Production Operating Curves. 
A relative measure of the throughput time is the flow rate. If, in analogy to the Funnel Formula the relative WIP is set in relation to the utilization we obtain the mean weighted flow rate as a normalized parameter for the range. This can also be calculated through the ratio of range to minimum range.

\section{Practical Applications of Logistic Production Operating Curves}

Logistic Production Operating Curves enable the logistic controlling of production processes. They are applicable in different industries. Specially developed control methods such as the Bottleneck Oriented Logistic Analysis make it possible to evaluate and improve existing production processes by describing them qualitatively and quantitatively, from a logistic perspective (Nyhuis and Wiendahl, 2009; Nyhuis and Penz, 1995). The specific causes of problems can then be localised and presented in the form of cause-and-effect relationships. Furthermore, the existing logistic potentials for improvement as well as the possible measures for developing them can be demonstrated and evaluated.

The basis of production control is the structured analysis of production processing data. The logistic analysis of this data is based on a well delineated, but complex problem. 'Well delineated' means here that there is enough data to extensively document the problem. The problem's complexity is for example due to the interactions between the workstations or because a number of related but partially contradicting objectives have to be simultaneously considered. The production processing data can be aggregated into key figures, such as a workstations mean WIP or output rate. They thus first provide information about the workstation's logistic behaviour.

Demonstrating the practical applications of the Logistic Production Operating Curves an excerpt of a Bottle-neck Oriented Logistic Analysis accomplished at a manufacturer of printed circuit boards is given. The target of the analysis was on the one hand a reduction of the order throughput times and on the other hand a reduction of the WIP. The left side of figure 10 shows a section of the material flow diagram for the observed manufacturer. Here, we can see that the workstation "resist coating" is a key station, because most of the material flow lines pass this workstation.

The right side of figure 10 shows a logistic portfolio. It illustrates that on the one hand the workstation "resist coating" runs at a very high WIP level. This comparison is made by the use of the normalised Logistic Production Operating Curves. On the other hand this workstation shows an outstanding throughput time proportion. The throughput time proportion is the ratio of the sum of the workstation's throughput times to the sum of the through times of the production analysed. So the workstation "resist coating" has the highest influence on the production's throughput times. Therefore, this workstation is examined in detail.

Firstly, the order's processing behaviour on the workstation "resist coating" is determined and visualized using a throughput diagram (figure 11). The output curve shows the outgoing orders' accumulated work content during the investigation period. It has a constant slope. Therefore, the workstation's output rate reveals no significant fluctuations. The input curve visualises the accumulated work content of the incoming orders. The input curve's slope indicates certain fluctuations, which can be traced back to the workstation's varying load. The WIP level on the workstation therefore also oscillates, because it results from the difference between the in- and output. By using the previously determined key figures together with the throughput diagram the behaviour of the workstation's logistic system can be evaluated. 

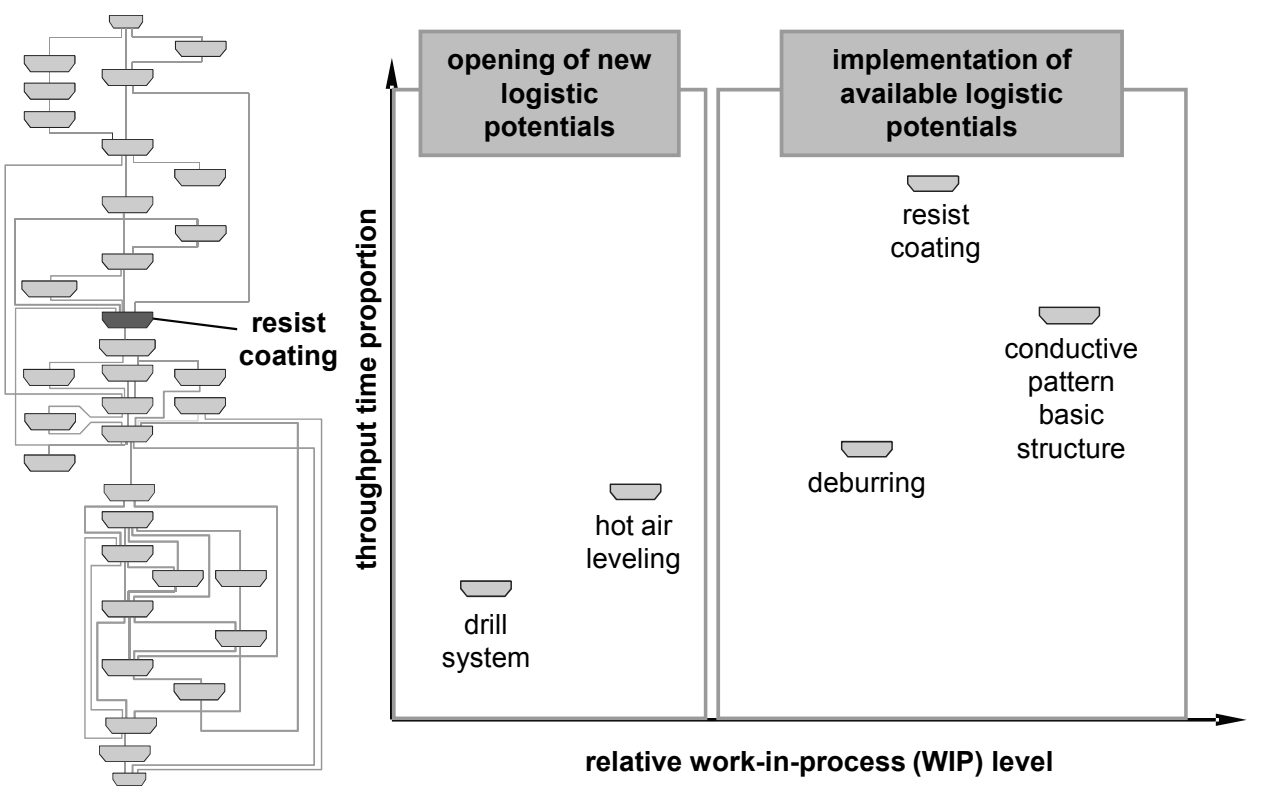

Fig. 10. Material Flow Diagram and Logistic Portfolio.

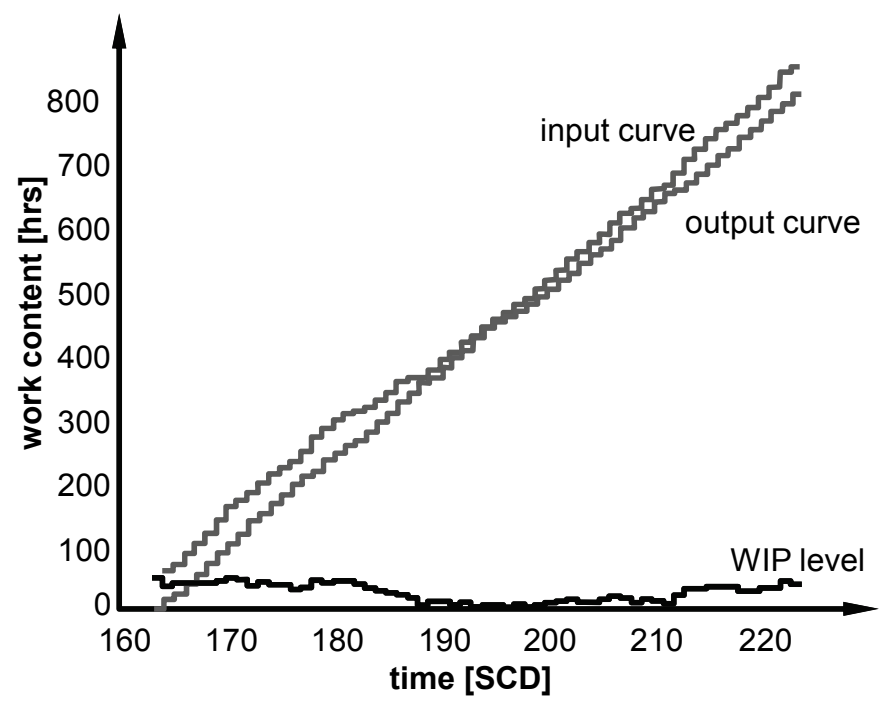

Fig. 11. Throughput Diagram of the Work Station Resist.

To identify logistic potential for improvement the relationships between the logistic objectives must be described. Therefore, the Logistic Production Operating Curves are used (figure 12). The calculated operating point is located well into the overload operating state and the WIP level on the workstation is very high. The output rate is therefore high, but 
there are also long throughput times. Reducing the WIP by approximately 22 hours would make it possible to reduce the throughput time by ca. $75 \%$ (from 2 SCD down to 0.5 SCD), without notable output rate losses.

As can be seen in figure 10, due to the workstation's central role reducing the WIP and therefore also the throughput time would affect the entire manufacturing process. In order to reduce the WIP of the workstation, the company could introduce measures that temporarily increase the output rate either through over-time or additional shifts. In total the capacity needs to be increased by 20 hours. This would be possible because the resist coating workstation had worked up until now with an output rate of 13.4 hours per shop calendar day. This however influences the work-stations downstream, which then have to ensure that the resulting additional load is processed through capacitive measures. Otherwise, the WIP problem is only transferred to the following workstations (Nyhuis and Penz, 1995).

Another approach to lowering the WIP on the resist coating workstation is to limit the load by temporarily restricting the order input. This has to be controlled through the order release. Here, it has to be considered that the disruption of the material flow at the input could lead to a loss of output on the workstations located upstream the resist coating station.

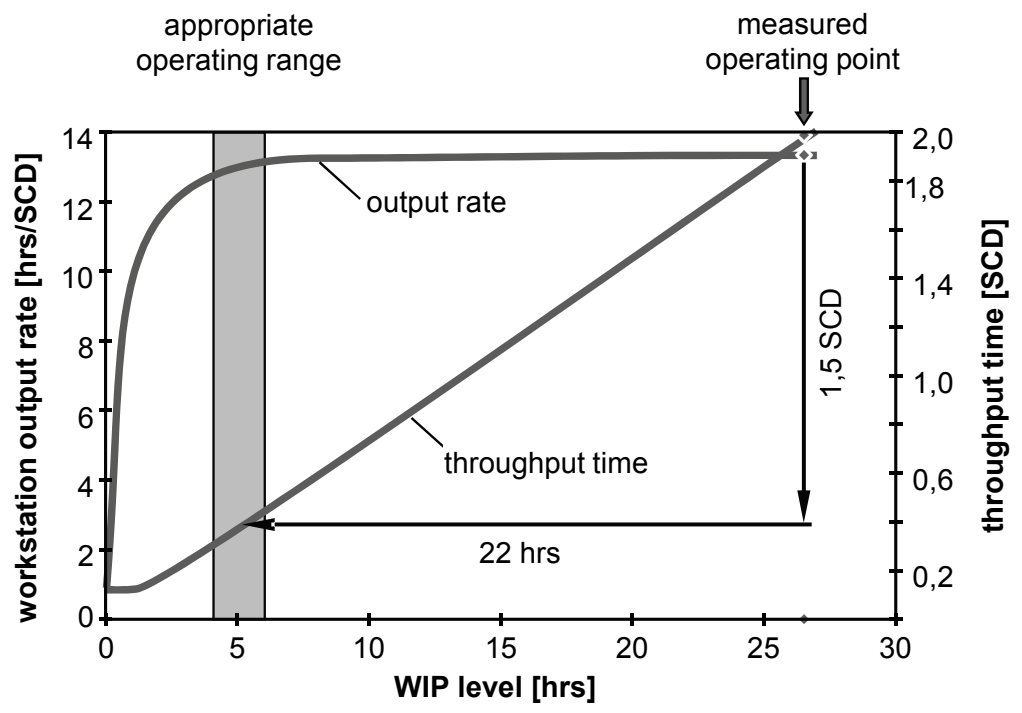

Fig. 12. Logistic Production Operating Curves of the Work Station Resist Coating.

\section{Derivation of the Schedule Adherence Operating Curve}

The measures described above will reduce the production's throughput times as well as the scatter of the throughput times. To be able to estimate the impact on the schedule adherence of production analysed which directly determines the delivery reliability, the Schedule Adherence Operating Curve was developed at the Institute of Production Systems and Logistics recently. To clarify the derivation of this model figure 13 illustrates a simulated 
histogram of a production's output date deviation which is weighed with the order value during a reference period of one year.

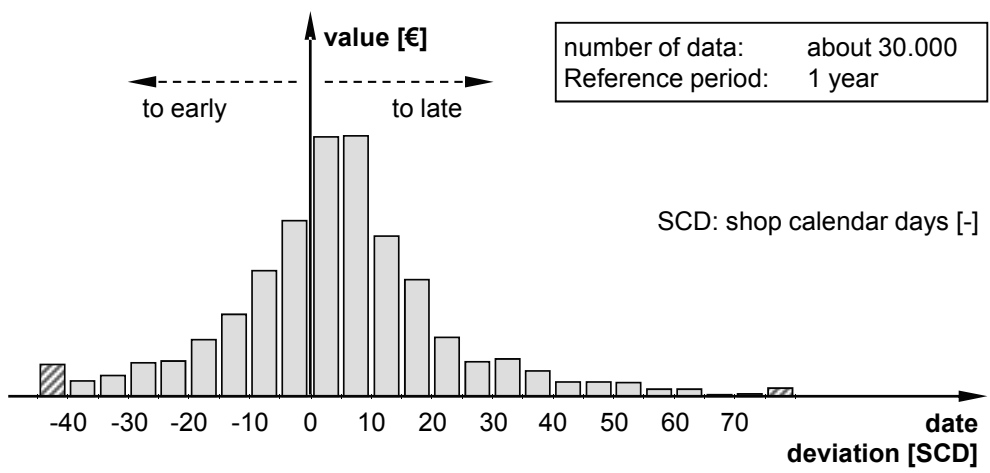

Fig. 13. Typical Distribution of a Production's Date Deviation.

The classes of the date deviations are plotted on the $x$-axis. The y-axis reflects the order value of a class. It is typical for such a distribution to be similar to a normal distribution. The weighted average is just under 5 SCD and a standard deviation is about 20 SCD. The grey striped bars on the left and right edge of the histogram represent all orders with a date deviation of less than 40 SCD and more than 75 SCD, respectively. As a result, there is an intolerable date situation as a result of the broad scattering of date deviation and the high number of orders delayed. This has a significant impact on the supply of internal and external customers and thus the delivery reliability. Overall, only about one-third of the orders are completed on time. The other orders leave production stage late. A higher schedule adherence can be achieved with an increased stock of finished orders. To determine this stock and to explain the connection between the mean weighted schedule adherence and the stock of finished orders depending on the distribution of the date deviation, the distribution of figure 13 should be considered in more detail. Therefore, the value weighted distribution of the date deviation is illustrated in the upper part of figure 14 again. This illustrates that a delivery time buffer, which is defined as a buffer time between the target finishing date and the target delivering date of the orders to the customer, is a key control variable in the field of tension between a high schedule adherence and a low level of stock of finished orders.

In the lower part of figure 14, the order values of the individual date deviation classes of the upper part are cumulated in a graph. It shows the part of orders which will be finished on time (before or on the target finishing date plus a defined delivery time buffer). This value corresponds to the weighted schedule adherence. In the case of a buffer with an assumed time of 0 SCD, the weighted schedule adherence is 35\%. But orders which are completed on time generate stock, because the majority of them are finished before the target finishing date (dark grey bars in histogram). In order to weight this stock with the time period of early completion, the stock area of the finished orders will be determined by calculating the integral below the curve of the cumulated value from negative infinity to a determined delivery time buffer of 0 BKT. In case a, the stock area of the finished orders has a value of 1,700 million $€ \cdot$ SCD. 
case a: delivery time buffer 0 SCD

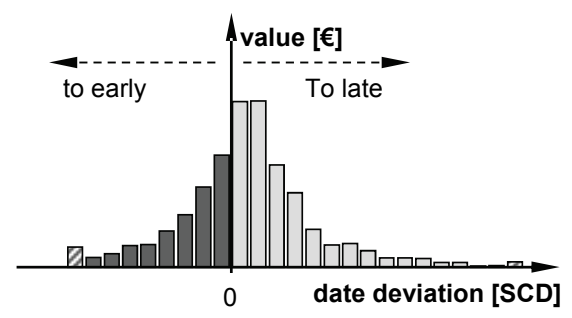

case b: delivery time buffer 10SCD

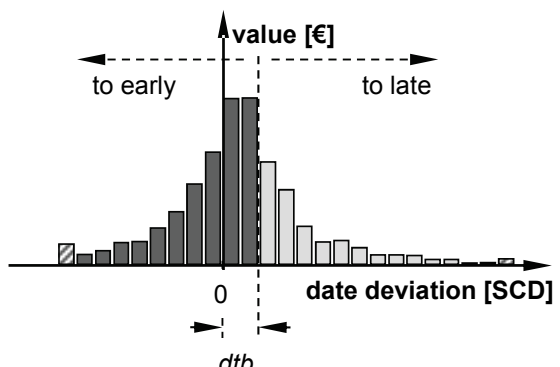

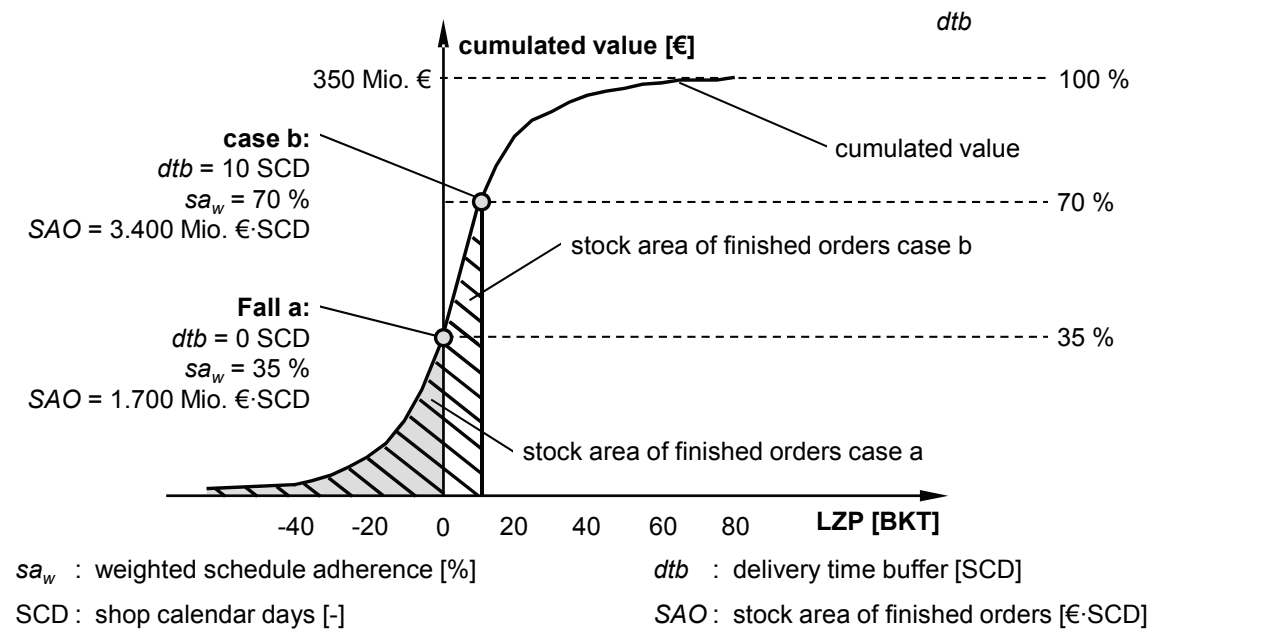

Fig. 14. Delivery Time Buffer as a Key Control Variable.

In case b, a delivery time buffer of 10 BKT is set exemplarily. The corresponding histogram in the upper part represents that a lot more orders leave the production stage without delay using the delivery time buffer (dark grey bars). The curve of the cumulated value in the lower part of figure 14 shows a weighted schedule adherence of $70 \%$. The stock area of finished orders is approximately 3,400 million $€$. SCD.

However, the stock area of finished orders is not sufficient to compare different schedule adherence scenarios with a similar order structure in terms of their values and their date deviations, because the stock area of finished orders depends on the selected reference period. Therefore, the mean stock level of finished orders can be calculated by dividing the stock area of finished orders by the selected reference period. To develop this knowledge into an effect model the upper part of figure 15 shows three curves of the cumulated value with different delivery time buffers and corresponding stock areas.

Case a shows an assumed delivery time buffer of 0 SCD. The result is a low schedule adherence and a small stock area of finished orders. Case $b$ represents a larger delivery time buffer. Accordingly, we find the values of the schedule adherence and the stock area of finished orders in a middle range. In case c, the delivery time buffer is adopted generously. The schedule adherence is close to $100 \%$, which is the result of a large stock area of finished orders. 

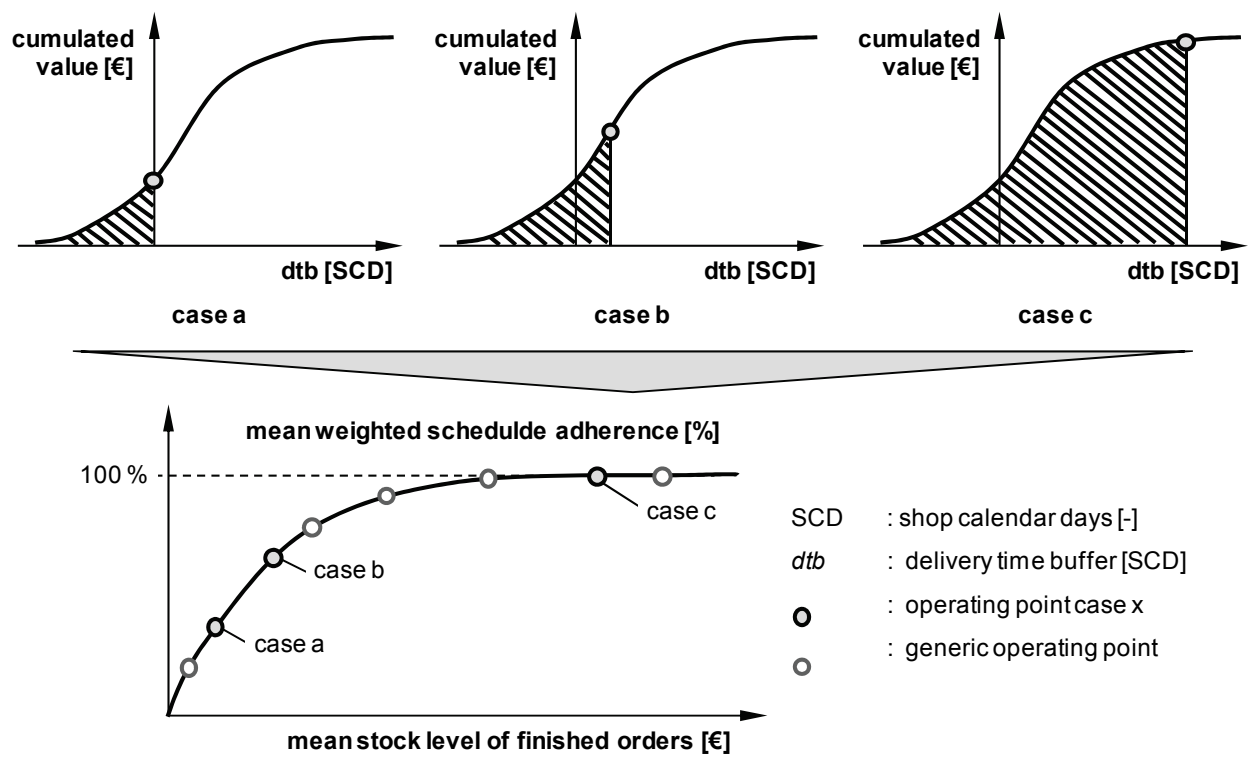

Fig. 15. Qualitative Derivation of the Schedule Adherence Operating Curve.

The respective stock level of finished orders is calculated for the cases $a, b$ and $c$. In the lower part of figure 15 the case-specific schedule adherence is confronted with the corresponding mean stock level of finished orders and illustrated in one chart. The grey rimmed points with white filling present generic operating points which might be generated by a modification of the delivery time buffer. If a large number of such pairs of values is plotted in a graph, the result is the Schedule Adherence Operating Curve.

This kind of modelling ensures the independence of the Schedule Adherence Operating Curve from the kind of statistic distribution of the date deviation. Now, it is possible to position a production stage in the field of tension between high schedule adherence and a low stock level of finished goods. Figure 16 shows this exemplarily. It is possible to calculate the stock of finished orders which is needed to ensure a target schedule adherence. The Schedule Adherence Operating Curve shows that an assumed schedule adherence of 95\% can be achieved by a mean stock level of finished goods of $S_{1}$. To position the production stage on this operating point, the delivery time buffer is the key control variable. This variable has to be considered critically because in practice, a delivery time buffer is connected with an earlier release of production orders. Thus, in principle, the planned throughput time will be increased which directly extends the delivery time to the customer. It is also possible that the so-called vicious cycle of production planning and control is triggered (Plossl 1973; Wiendahl 2008).

The Schedule Adherence Operating Curve can be used to determine potentials which result from structural changes. For this purpose a mathematical description of this Operating Curve is required. The formula is based on an approximate equation. It is assumed that the distribution of order values over the output date deviation after the implementation of measures that cause the structural changes especially regarding the throughput times is similar to a normal distribution. This function is determined by the mean value and the 
standard deviation of the distribution as well as by the variable date deviation (Kühlmeyer 2001).

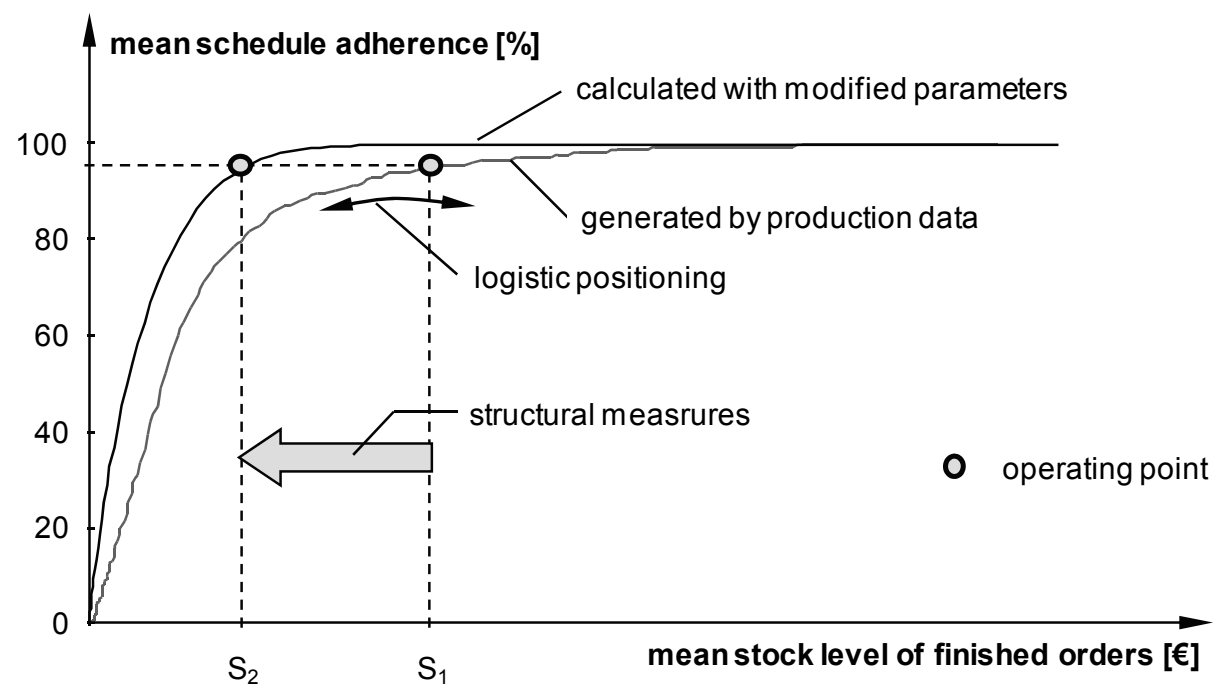

Fig. 16. Schedule Adherence Operating Curve.

$$
v o(d d ; \mu ; \sigma)=\operatorname{OUT} \cdot \frac{1}{\sigma \sqrt{2 \Pi}} \cdot e^{\frac{(d d-\mu)^{2}}{2 \sigma^{2}}}
$$

$\begin{array}{ll}\operatorname{vo}(\mathrm{dd} ; \mu ; \sigma) & \text { value of orders with a specific date deviation }[€] \\ \mathrm{dd} & \text { date deviation }[\mathrm{SCD}] \\ \mu & \text { mean value of the date deviation [SCD] } \\ \sigma & \text { standard deviation of the date deviation }[\mathrm{SCD}] \\ \text { OUT } & \text { output in the reference period }[€]\end{array}$

The integral of this function from negative infinity up to the assumed delivery time buffer allows the estimation of the value of orders which leave the production stage on time.

$$
v o o(d t b ; \mu ; \sigma)=\text { OUT } \cdot \frac{1}{\sigma \sqrt{2 \Pi}} \cdot \int_{-\infty}^{d t b} e^{\frac{(d d-\mu)^{2}}{2 \sigma^{2}}} d d d
$$

$\operatorname{voo}(\mathrm{dtb} ; \mu ; \sigma) \quad$ value of orders finished on time $[€]$

$\mathrm{dtb} \quad$ delivery time buffer [SCD]

The mean weighted schedule adherence is calculated by dividing this value by the output in the reference period.

$$
s a_{m w}(d t b ; \mu ; \sigma)=\frac{1}{\sigma \sqrt{2 \Pi}} \cdot \int_{-\infty}^{d t b} e^{\frac{(d d-\mu)^{2}}{2 \sigma^{2}}} d d d
$$

$\mathrm{sa}_{\mathrm{mw}}(\mathrm{dd} ; \mu ; \sigma) \quad$ mean weighted schedule adherence [-] 
Calculating the integral of equation 8 again determines the stock area of finished orders. The mean stock level of finished orders is the result of the division of the stock area of finished orders by the reference period.

$$
s f o_{m}(d t b ; \mu ; \sigma)=\frac{\text { OUT }}{r p} \frac{1}{\sigma \sqrt{2 \prod}} \cdot \int_{-\infty}^{d t b} \int_{-\infty}^{d t b} e^{\frac{(d d-\mu)^{2}}{2 \sigma^{2}}} d d d \cdot d d d
$$

$\mathrm{sfo}_{\mathrm{m}}(\mathrm{dd} ; \mu ; \sigma) \quad$ mean stock level of finished orders $[€]$

rp reference period [SCD]

The Schedule Adherence Operating Curve can be described in parameterized form by equations 9 and 10. Mainly, the calculated Schedule Adherence Operating Curve is applied to represent potentials, which result from structural changes within the production stage and lead to a change of the behaviour of the throughout times and consequently the date deviation.

Next to the generated curve, figure 16 represents a Schedule Adherence Operating Curve which is calculated according to equation 9 and 10. A changed behaviour of the date deviation has a direct effect on the parameters of the Operating Curve (mean value and standard deviation of date deviation). If the company is able to realise measures in a way to reduce the scatter of the output date deviation, the form of the Schedule Adherence Operating Curve is influenced directly. Consequently, this opens new potentials to be realized. Figure 16 shows that now, in order to realise the target schedule adherence of $95 \%$ only the mean stock level of finished orders $S_{2}$ is required. This stock level can be adjusted by a corresponding lower delivery time buffer.

Only few data is necessary to establish the Schedule Adherence Operating Curve: the order number, the output date deviation of the order and a weighted value. An evaluation of the order with their monetary values seems to be the most meaningful evaluation parameter, because the stock cost caused can be estimated directly through it. In principle, other parameters like weight could also be considered. The Schedule Adherence Operating Curve provides a simple possibility to estimate potentials regarding the stock of finished orders and the mean weighted schedule adherence, which affects directly the logistical performance towards the customer.

\section{Practical Alication of the Sedule Aerence Operating Curve}

To discuss the practical Application of the Schedule Adherence Operating Curve we concentrate on the analysed production stage of the manufacturer of printed circuit boards again (see chapter 4). Figure 17 shows the output date deviation of the production stage.

The mean delay is $4.5 \mathrm{SCD}$ and the scatter of the date deviation is close to $10 \mathrm{SCD}$. The result is low schedule adherence. This can also be seen in figure 18. The actual operating point shows a date adherence of $34 \%$ with a delivery time buffer of 0 SCD causing a mean stock level of finished orders of $59.100 €$.

To reach the target date adherence of $95 \%$ by increasing the delivery time buffer up to 15 SCD a mean stock level of 590,000 $€$ is required (measure 1). If the scatter of the output date deviation can be reduced to about 5 SCD by measures described in chapter 4 it is possible to realise the target date adherence with a delivery time buffer of 5 SCD. This will lead to a mean stock level of finished orders of $240,000 €$. 


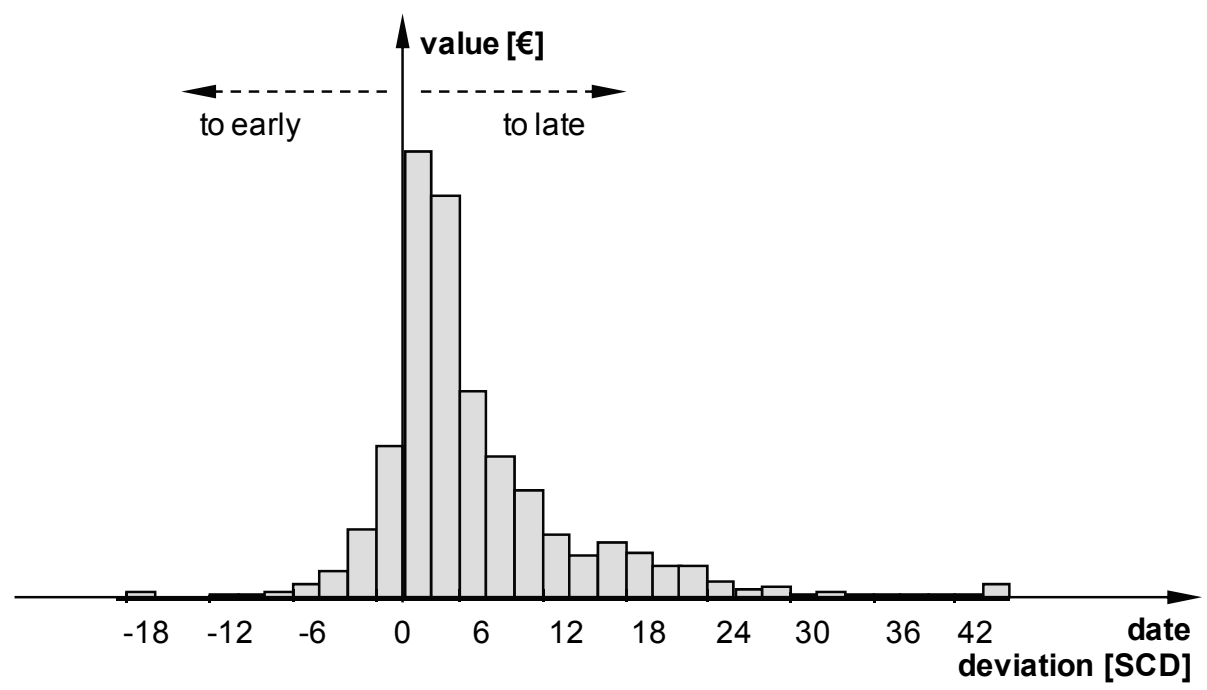

Fig. 17. Output Date Deviation of the Productions Stage.

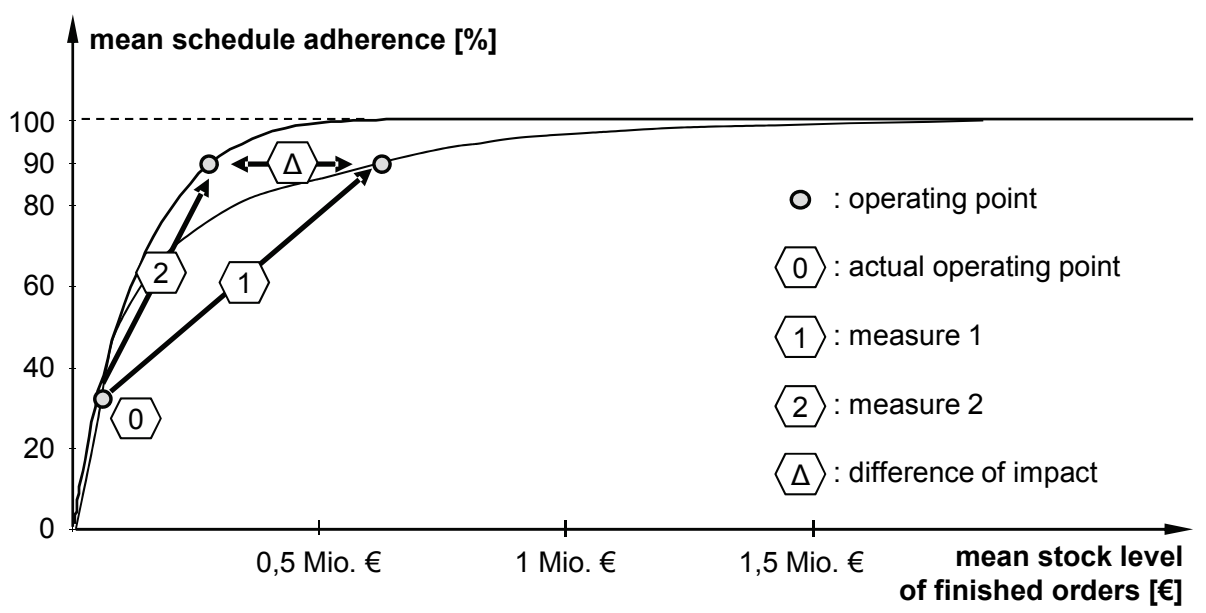

Fig. 18. Output Date Deviation of the Productions Stage.

\section{Conclusions}

A main challenge of production management is the logistic positioning in the field of tension between the logistic objectives utilization, throughput time, delivery reliability and WIP. These contradicting logistic objectives form what is commonly known as the 'Dilemma of Operations Planning'. In order to make the Dilemma of Operations Planning controllable, it is necessary to position the target operating points amidst the 'field of tension' created by these competing logistic objectives. This is possible with the help of the Logistic Operating Curves. Therefore, this paper showed the derivation of the Logistic Production Operating 
Curves and the Schedule Adherence Operating Curve. These models are thus an ideal foundation for supporting and monitoring a company's processing reliability and capability and can be drawn upon when evaluating the process during production controls.

An example of a practical application of the Logistic Operating Curves was given in the paper. The industrial application was conducted in a printed circuit boards manufacturing. For this manufacturing potentials were shown on the one hand of reducing throughput times and WIP without a significant loss of output rate and on the other hand of increasing the date adherence with a tolerable mean stock level of finished orders. Further practical applications are summarized by Nyhuis (Nyhuis, 2007).

The principle of mapping the relationships of the effects between the production logistics performance measures by means of the Logistic Operating Curves technique was transferred to other areas of industrial production. For example the Logistic Operating Curves for inventory processes map the mean stock holding time and the mean delivery delay for a product or group of products in relation to the mean inventory level (Lutz, 2002; Gläßner, 1995; Schmidt and Wriggers, 2008).

Altogether the IFA wants to establish a comprehensive Logistic Operating Curves Theory which enables a model-based description of all production logistics performance measures. This theory provides an easy-to-use method for companies with any type of manufacturing organisation.

\section{References}

Enslow, B. (2006). Best Practices in International Logistic, Aberdeen Group, Boston

Gläßner, J. (1995). Modellgestütztes Controlling der Beschaffungslogistischen Prozesskette, Leibniz University Hannover, Hanover

Gutenberg, E. (1951). Grundlagen der Betriebswirtschaftslehre, Springer, Berlin

Hon, K. K. B. ( 2005). Perfomance and Evaluation of Manufacturing Systems. Annals of the CIRP, Vol. 54, No. 2, 675-690

Hopp, W. J., Spearman, M. L. (2000). Factory Physics, Foundations of Manufacturing Management, Irwin/McGraw-Hill, New York

Kim, J. H., Duffie, N. A. (2005). Design and Analysis of Closed-Loop Capacity Control for a Multi-Workstation Production System. Annals of the CIRP, Vol. 54, Mo. 1, 455-458.

Kühlmeyer, M.: Statistische Auswertungsmethoden für Ingenieure. Springer, Berlin et al., 2001.

Lutz, S. (2002). Kennliniengestütztes Lagermanagement, Leibniz University Hannover, Hanover

Nyhuis, P., von Cieminski, G., Fischer, A. (2005). Applying Simulation and Analytical Models for Logistic Performance Prediction. Annals of the CIRP, Vol. 54, No. 1, 417422

Nyhuis, P., Wiendahl, H.-P. (2009). Fundamentals of Production Logistics. Springer, Berlin

Nyhuis, P., Penz, T. (1995). Bottleneck-oriented Logistic Analysis as a Basis for Business Reengineering, In: Reengineering the Enterprise, Browne, J., O'Sullivan, D. (Ed), Chapman \& Hall, London

Nyhuis, P. (2007). Practical Applications of Logistic Operating Curves. Annals of the CIRP, Vol. 56, No. 1, 483-486

Plossl, G. W.: Manufacturing Control - The Last Frontier for Profits. Reston Publishing Company, Reston, 1973. 
Schmidt, M., Wriggers, F. S. (2008) Logistische Modellierung von Lagerprozessen, In: Beiträge zu einer Theorie der Logistik, Nyhuis, P. (Ed.), 139-155, Springer, Berlin

Schönsleben, P. (2004). Integral Logistics Management, 2nd edition, St Lucie Press, Boca Raton Schuh, G. (2006). Produktionsplanung und Steuerung, 3rd edition, Springer, Berlin

Wiendahl, H.-P. (1997). Fertigungsregelung: Logistische Beherrschung von Fertigungsabläufen auf Basis des Trichtermodells, Carl Hanser, München

Wiendahl, H.-P.: Betriebsorganisation für Ingenieure. $6^{\text {th }}$ edition, Hanser, München, Wien, 2008.

Wildemann, H. (2007). Logistik-Chek, 5th edition, TCW, Munich 


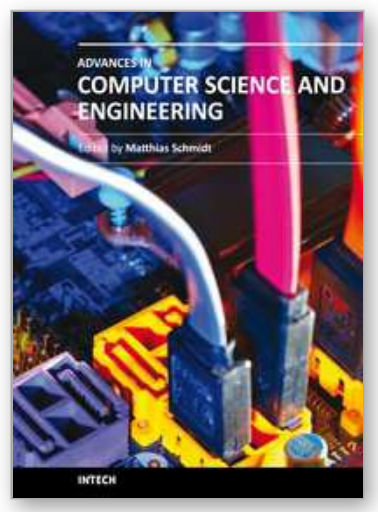

\author{
Advances in Computer Science and Engineering \\ Edited by Dr. Matthias Schmidt
}

ISBN 978-953-307-173-2

Hard cover, 462 pages

Publisher InTech

Published online 22, March, 2011

Published in print edition March, 2011

The book Advances in Computer Science and Engineering constitutes the revised selection of 23 chapters written by scientists and researchers from all over the world. The chapters cover topics in the scientific fields of Applied Computing Techniques, Innovations in Mechanical Engineering, Electrical Engineering and Applications and Advances in Applied Modeling.

\title{
How to reference
}

In order to correctly reference this scholarly work, feel free to copy and paste the following:

Peter Nyhuis and Matthias Schmidt (2011). Logistic Operating Curves in Theory and Practice, Advances in Computer Science and Engineering, Dr. Matthias Schmidt (Ed.), ISBN: 978-953-307-173-2, InTech, Available from: http://www.intechopen.com/books/advances-in-computer-science-and-engineering/logistic-operatingcurves-in-theory-and-practice

\section{INTECH}

open science | open minds

\author{
InTech Europe \\ University Campus STeP Ri \\ Slavka Krautzeka 83/A \\ 51000 Rijeka, Croatia \\ Phone: +385 (51) 770447 \\ Fax: +385 (51) 686166 \\ www.intechopen.com
}

\author{
InTech China \\ Unit 405, Office Block, Hotel Equatorial Shanghai \\ No.65, Yan An Road (West), Shanghai, 200040, China \\ 中国上海市延安西路 65 号上海国际贵都大饭店办公楼 405 单元 \\ Phone: +86-21-62489820 \\ Fax: +86-21-62489821
}


(C) 2011 The Author(s). Licensee IntechOpen. This chapter is distributed under the terms of the Creative Commons Attribution-NonCommercialShareAlike-3.0 License, which permits use, distribution and reproduction for non-commercial purposes, provided the original is properly cited and derivative works building on this content are distributed under the same license. 